\title{
Conciencia histórica y relatos identitarios: en búsqueda de una ética de la experiencia social de la historia ${ }^{1}$
}

\author{
Historical consciousness and identity stories: \\ searching for an ethic of history'social experience
}

\author{
Miguel Ángel Guzmán López ${ }^{2}$ \\ Universidad de Guanajuato, México
}

Recepción: 06 de junio del 2020

Evaluación: 02 de julio del 2020

Aceptación: 20 de julio de 2020

1 Este artículo deriva del proyecto de investigación homónimo Conciencia histórica y relatos identitarios: en búsqueda de una ética de la experiencia social de la historia, realizado al interior del equipo de investigación que conforma la línea de Generación y Aplicación del Conocimiento de Teoría y Filosofía de la Historia, de la Universidad de Guanajuato.

2 Licenciado en Historia y Doctor en Filosofía por la Universidad de Guanajuato. Investigador Nivel 1 en el Sistema Nacional de Investigadores de México.

Correo electrónico: miguelguzmanlop2@gmail.com 


\title{
Resumen
}

Este trabajo pretende hacer un análisis a partir de tres preguntas fundamentales. La primera de ellas: ¿Cómo puede derivar una propuesta de carácter ético de un concepto hermenéutico-ontológico de la conciencia histórica?, en el entendido de que en una primera instancia la teoría hermenéutica gadameriana se preocupa por el aspecto situacional-ontológico del sujeto, mientras que acerca de la parte ética no se encuentra un desarrollo teórico comparable en profundidad. La segunda pregunta reza: ¿Qué es lo que debe entenderse por relatos identitarios y cuáles son sus repercusiones teóricas?, dado que aquí se plantea que en dichos relatos se encuentra manifiesta la conciencia histórica de tal manera que es susceptible de ser historiada. Y finalmente, la tercera pregunta es ¿Qué respuesta puede darse a la pregunta de qué debe hacerse desde la historia acontecida?, que lleva la reflexión hacia el campo de la ética, en el sentido de preguntarse por la conciencia histórica desde la experiencia social en favor de un proyecto para el futuro.

Palabras clave: conciencia histórica, discursos identitarios, ética.

\begin{abstract}
This work aims to make a analysis based on three fundamental questions. The first of which is: How can a proposal of an ethical nature derive from a hermeneutic-ontological concept of historical consciousness?, in the understanding that, in a first instance, Gadamerian hermeneutical theory is concerned with the situational-ontological aspect of the subject, while on the ethical side there is no in-depth comparable theoretical development. The second question: What is to be understood by identity stories and what are their theoretical repercussions?, given that here it is stated that in these stories historical consciousness is manifested in a way that is capable of being historized. And finally, the third question is: What answer can be given to the question of what should be done from the history that one has?, which leads reflection to the field of ethics, in the sense of asking about historical consciousness from experience social in favor of a project for the future.
\end{abstract}

Keywords: historical consciousness, identity discourses, ethics. 
En la medida en la que el rostro del Otro nos pone en relación con el tercero, la relación metafísica del yo con el Otro se desliza hacia la forma del Nosotros, aspira a un Estado, a las instituciones, a las leyes, que son la fuente de la universalidad (Levinas, 1977, p. 276).

Si se piensa en la conciencia histórica a partir de consideraciones hermenéutico-ontológicas, es necesario estar al tanto de tres premisas fundamentales:

La primera sostiene que la conciencia histórica es ante todo darse cuenta uno mismo de la condición existencial del Dasein ${ }^{3}$ (Heidegger, 2002). Uno mismo sabe que participa de la condición existencial del ser-ahí pero no lo agota, por lo que tener conciencia histórica, en primera instancia, es saberse Dasein.

La segunda plantea que tomar conciencia de ello no ocurre sino mediante la relación que establece el Dasein con el mundo, relación que es necesariamente dialógica dado el carácter comprensivo del ser-ahí, pues dicho carácter implica la interacción del ser-ahí con el mundo en constante estado de apertura. Apertura, interacción y tiempo son tres claves importantes para entender las diversas tensiones dialógicas que el ser-ahí desarrolla en su propia facticidad, pues de eso se constituyen la historicidad y la efectualidad de la historia ${ }^{4}$ (Gadamer, 1998). Saberse Dasein es saberse en diálogo con el mundo.

La tercera, finalmente, señala que el diálogo con el mundo en interpelación continua es un concernir total. El Dasein, por ello, encara lo que le sale al paso de diferentes formas, todas ellas en incumbencia con el mundo, incluso la indiferencia, pues la indiferencia concierne a quien la ejerce. No es extraño que el ser-ahi tenga la actitud crítica como una posibilidad. Entonces, saberse en diálogo con el mundo es saberse potencialmente crítico.

3 En la filosofía de Heidegger, el Dasein o ser-ahí, es un ente cuya manera de ser es la existencia, no entendida como presencia, sino como posibilidad de ser o no ser. Un ente cualquiera (como una silla o una mesa) cambia en el tiempo, pero no experimenta ese cambio, no lo percibe, y por tanto no puede proyectar su ser como una expectativa. El Dasein es el ente que no solamente puede contar con esa experiencia, sino que le es esencial para llegar a ser lo que es.

4 En el pensamiento de Gadamer, la historia efectual hace referencia al devenir histórico, al acontecer real que determina irremediablemente a los hombres, razón por la cual éstos no pueden contraponerse a su pasado desde un lugar ajeno al devenir histórico mismo, desde una posición trascendente al acaecer de los hechos. De esta manera, el sujeto no puede entender la historia desde fuera de ella, sino solamente inmerso en la misma, siendo él parte del acontecer.

Guzmán, M. (2020). Conciencia histórica y relatos identitarios: en búsqueda de una 
Estas premisas permiten señalar que en la constitución de la conciencia histórica existe un fundamento ontológico, un carácter hermenéutico y una posibilidad ética, que en conjunto contienen el germen de la universalidad de este concepto, pues con ello no es necesario remitirse a un tipo de individuo o de sociedad en particular, ni a un momento histórico específico. No se atribuye la conciencia histórica a una cultura o a una civilización, ni a una sola forma política de ver el mundo: la conciencia histórica es una para todo aquel que la experimenta.

Teniendo en cuenta lo anteriormente enunciado, este trabajo pretende desarrollar una reflexión inicial acerca de las diversas posiciones estratégicas que están implícitas en los relatos identitarios ${ }^{5}$, a través de los cuales la conciencia histórica de una comunidad determinada se expresa en pos de un proyecto que permita sugerir qué debe hacerse desde la historia y con la conciencia histórica que se tiene en la actualidad. Si la conciencia histórica se encuentra manifiesta en los relatos identitarios y en ellos se encara a la tradición desde una perspectiva que puede ser crítica, pero difícilmente neutral, las cuestiones que deriven de este punto pueden conducir la reflexión hacia el campo de la ética, en el sentido de preguntarse por lo que debe hacerse desde la historia y con la conciencia histórica desde la experiencia social, con la meta de un proyecto para el futuro.

Este es el punto central del planteamiento. En este contexto surgen preguntas tales como ¿cómo puede derivar una propuesta de carácter ético de un concepto ontológico de la conciencia histórica? ¿Qué es lo que debe entenderse por discursos identitarios y cuáles son sus repercusiones teóricas? ¿Hay en

\footnotetext{
5 En este trabajo se entiende por relatos identitarios a todas aquellas narraciones orientadas a dar cuenta del pasado de una comunidad o del individuo en una comunidad determinada, que tiene como finalidad, explícita o no, generar un sentimiento de pertenencia o de otredad en las sociedades que los asumen. Pueden adoptar diferentes formas como la historiografía, el mito, la leyenda, la literatura en general y el discurso político. Su carácter es transdisciplinar, pues, por ejemplo, en la medida en la que en ellos se puede dar cuenta del pasado de una comunidad son de interés para el historiador o para el antropólogo, mientras que, como construcciones dotadoras de sentido, son de interés del análisis filosófico-hermenéutico. Cabe resaltar que el término se está empleando desde una perspectiva social y no desde un punto de vista exclusivamente individual, como lo propone Martin Payne (2002) para efectos psico-terapéuticos, aunque claramente existan puntos en común entre la conformación de una identidad individual y la de una colectiva. La diferencia estribaría en que más que hablar de un proceso psicológico de construcción de identidades, estamos haciendo referencia a un proceso de comunicación y participación de elementos dotadores de sentido entre grupos sociales, como parte del ser en el mundo hermenéutico.
} 
ellos usos estratégicos y/o posturas ideológicas que incidan sobre la experiencia social de la historia? ¿Qué respuesta puede darse a la pregunta ética de 'qué debe hacerse' desde la trayectoria histórica que las generaciones del presente han heredado de sus antepasados?

\section{Punto de partida: la historia efectual y la conciencia en torno a ésta}

El punto de partida que llevará a la consideración de la dimensión ética de la proposición ontológica anteriormente descrita, tiene que ver en primera instancia con las nociones gadamerianas de 'historia efectual' y de 'conciencia de la historia efectual'.

La historia efectual supone el acontecer real que determina a los individuos irremediablemente y por lo cual éstos no pueden contraponerse a su pasado desde un lugar ajeno al devenir histórico mismo, desde una posición trascendente al acaecer de los hechos (Gadamer, 1998, p. 137). Por ello el sujeto no puede entender la historia desde fuera de ella, sino solamente inmerso en la misma, siendo él parte del acontecer: "No se trata entonces de una comprensión de la historia como un transcurso, sino de una comprensión de aquello que nos sale al paso en la historia interpelándonos y concerniéndonos" (Gadamer, 1998, p. 136). La historia nos sale al paso, nos interpela en la medida en que estamos determinados por ella, en que constituimos parte y producto de ella, y siempre nos concierne por muy ajena que en un principio pudiera parecer.

En consecuencia, una conciencia histórico-efectual es la conciencia de la situación hermenéutica, es decir, "la situación en la que nos encontramos frente a la tradición en que queremos comprender" (Gadamer, 1998, p. 372). Se está en una situación y no frente a ella, dice Gadamer, y por tanto no se puede tener un saber objetivo de la misma. En consecuencia, no es posible dar cumplimiento por entero al conocimiento de una situación. Sucede lo mismo en lo que respecta a la situación hermenéutica: no se puede hacer la reflexión total sobre la historia efectual, puesto que no sólo se encuentra uno inmerso en ella, sino que el propio devenir histórico nunca está acabado. Al entenderse esta cuestión se está dando cuenta de la esencia misma del ser histórico. En este sentido, Gadamer afirma que "ser histórico quiere decir no agotarse nunca en el saberse” (Gadamer, 1998, p. 372). Muy relacionado con esto está el concepto de horizonte que denota el ámbito de visión que abarca y encierra todo lo que es visible desde un determinado punto (Gadamer, 
1998, p. 372). En términos de conciencia puede hablarse de estrechez de horizonte, de amplitud o apertura del mismo, etc. De esta manera puede afirmarse que quien no tiene horizontes:

(...) es un hombre que no ve lo suficiente y que en consecuencia supervalora lo que le cae más cerca. En cambio, tener horizontes significa no estar limitado a lo más cercano, sino poder ver por encima de ello. El que tiene horizontes puede valorar correctamente el significado de todas las cosas que caen dentro de ellos según los patrones de cerca y lejos, grande y pequeño (Gadamer, 1996, p. 373).

La elaboración de la situación hermenéutica "significa (...) la obtención del horizonte correcto para las cuestiones que se nos plantean de cara a la tradición" (Gadamer, 1996, p. 373). Pero el establecimiento de este horizonte correcto no implica que esto quede fijo de una vez por todas. Muy por el contrario, está en perpetuo movimiento: se desplaza al paso de quien se mueve (Gadamer, 1998, p. 375). Lo que se quiere decir con el horizonte correcto, en todo caso, implica ver las cosas desde su justa perspectiva al momento en que se hace la pregunta, pensando que, en un momento diferente, el horizonte correcto corresponderá a ese otro contexto.

De esta forma se puede apreciar cómo el proceso de la comprensión -la forma en que la comprensión acontece- constituye un desenvolvimiento historizado en el que, conforme ocurre, la conciencia sabe de sí misma desde su propia situación mientras se comprende en el mundo, es decir, se desempeña en él. Por ello Gadamer señala que la conciencia histórica efectual es más ser que conciencia (Gadamer, 1998, p. 18), es decir que da más cuenta de la naturaleza del ser que solamente de la forma en que el conocimiento se presenta como tal.

Por todo lo anteriormente dicho puede afirmarse que la conciencia hermenéutica tiene su centro mismo en su aspecto histórico efectual y que, por tanto, ya es conciencia histórica, dado que se ha visto ya que el carácter finito del ser y su desenvolvimiento hermenéutico están indisolublemente ligados con su historicidad.

\section{La tradición y su encaramiento}

En este sentido, la tradición ocupa un lugar importante porque en ella están depositados todos los elementos culturales que en el transcurso del tiempo se han ido "sedimentando" y generando una presencia continua. La continuidad 
de estos elementos culturales posibilita hacer referencia a la formación (Bildung) del individuo. La tradición genera una tensión dialógica entre sí y el ser-uno-en-cada-caso fáctico, pues al tiempo que el Dasein deviene temporalmente también lo hace históricamente, y esto significa que aunque se viva a cada momento un instante nuevo, nunca se es completamente inédito (se habla un lenguaje, se asume una forma de pensar específica, etcétera, todo ello heredado).

De entrada se puede suponer que el término es retomado en buena medida de Heidegger, quien define la tradición expresa como el retroceso a las posibilidades del "ser-ahi" "sido-ahí", la reiteración propia de una posibilidad de la existencia sida (Heidegger, 2002, p. 416). Pero las alusiones que Gadamer hace al término inducen a pensar que no lo retoma de manera idéntica a como lo hace Heidegger, sino que lo desarrolla de forma más amplia, y con ello parece efectivamente indicar que se trata de lo que es heredado históricamente, a lo que el ser-ahí pertenece en la medida en que es históricamente finito (García, 2004, p. 298), y que esta historia heredada lo envuelve en una dinámica en la que es necesario "avanzar hacia el futuro, para remediar las deficiencias del presente, lo cual, necesita un regreso al pasado" (García, 2004, p. 298), pero en el cual no hay alusión alguna al estado de propiedad que Heidegger considera como condición previa necesaria para poder hablar de una conciencia histórica en cuanto tal.

Gadamer percibe la tradición como una continuidad inmersa dentro de las constantes transformaciones del devenir histórico: "la tradición es esencialmente conservación, y como tal no deja de estar presente en los cambios históricos" (Gadamer, 1998, p. 349). Pero tal tradición no es ella misma inmutable, sino que se encuentra en constante cambio mediante la reafirmación que implica su vivencia por parte de los sujetos. La tradición, en ese sentido, es tradición viva ${ }^{6}$ (García, 2004, p. 299).

En otras palabras, lo que Gadamer señala es que la forma en la cual el individuo interactúa con el mundo es ineludiblemente comprensiva e histórica, aún antes de poder comprenderse a sí mismo reflexivamente. Dado que el

${ }^{6}$ La asunción de la tradición, por otra parte, no se reduce a una aceptación acrítica de lo heredado, sino que implica, en términos epistemológicos, el rechazo de la oposición abstracta que impuso el Iluminismo entre tradición e historia, por un lado, y el conocimiento, por el otro (Dobrosavljev, 2002, pp. 605-618). 
individuo está determinado históricamente - porque ese es su modo de ser-y porque en el devenir histórico, pese a los cambios, también se desarrollan elementos cuya presencia es continua, y con los cuales el individuo entra en contacto, de manera que éste está determinado por la tradición, constituida por esos elementos continuos.

En su cambiante presente el sujeto comprende la realidad y se desenvuelve en el mundo. Al hacerlo, necesariamente lo hace inmerso en la tradición, ya que ésta constituye, en primer lugar, la cuna en la cual el sujeto ha sido formado (gebildet) y, en segundo lugar, el asidero a partir del cual se llevan a cabo la comprensión y el desempeño. Esto constituye a la conciencia hermenéutica y también a la conciencia histórica; en ambas es fundamental el apego a la tradición y su tensión con el movimiento del sujeto.

Vale decir, entonces, que incluso la actitud crítica forma parte de la tradición, pues de lo contrario no se desarrollaría en ella la relación dialógica mencionada anteriormente, y se tendría por resultado que todo acto crítico sería totalmente inédito y no podría heredarse como una postura crítica: sería un acto aislado por su misma singularidad ${ }^{7}$ (Bengoa, 1992, p. 162).

De ahí que, en efecto, el reconocimiento de la tradición no implique un acto sumiso. La tradición puede encararse de diversas maneras y ninguna de ellas ad aeternum. Francisco Manuel López distingue al menos cuatro posturas del sujeto frente a la tradición: de pertenencia, de interpelación, de proclividad y de resistencia (López, 2009, p. 40). En el primero de los casos el individuo reconoce la relación vital que guarda respecto de la tradición; en el segundo, adopta una postura frente a un cuestionamiento que parte de la tradición; en el tercer caso, el individuo busca a la tradición y, en el cuarto caso la rechaza, en un acto crítico que puede ser aquel sobre el que Habermas y Apel, principales críticos de Gadamer, llaman la atención. Pero en ninguno de los casos el individuo se desvincula ontológicamente de la tradición, pues aún en el caso en el que se presenta el rechazo de una tradición específica, la alternativa que surge deriva siempre de otra tradición particular.

\footnotetext{
7 Ricoeur señala que el crítico, al apelar a la reflexión, habla justamente desde el lugar denunciado por él mismo como inexistente, del sujeto trascendental y, por tanto, desde el fondo de una tradición que sería la tradición Ilustrada y, aún más, desde la tradición de las acciones liberadoras, cuya remisión llega hasta los tiempos antiguos.
} 
En estas cuatro actitudes se presenta un reforzamiento identitario del individuo; es decir que con la postura que éste establece respecto a la tradición, sin importar el tipo de relación que tenga, se refuerza la conciencia que se tiene de ser sí mismo respecto a los demás, cosa que forma parte fundamental del carácter dialógico de la hermenéutica. Siendo la conciencia histórica al mismo tiempo conciencia hermenéutica, tal y como Gadamer plantea y, por tanto, expresión de la facticidad y de la finitud de la experiencia de ser-en-elmundo, la pregunta sobre la posibilidad que ésta tiene de ser crítica, no tendría por qué remitirnos fuera del discurso ontológico, toda vez que la actitud crítica se desprendería de una de las posibles formas de encarar la tradición sin perder por ello la dinámica dialogal de la hermenéutica.

Cuando se habla de la posibilidad crítica de la conciencia histórica no se está queriendo decir que la crítica sea una condición de posibilidad para la existencia de la conciencia histórica, sino que se trata de una de las formas en las que la conciencia histórica encara la tradición. Así como la conciencia histórica tiene, por un lado, la posibilidad de ser crítica, por otra parte, no puede eludir el efecto del uso estratégico del lenguaje, mediante el cual la aberración del mensaje y el ejercicio del dominio y la persuasión, sobre los que llaman la atención Habermas y $\mathrm{Apel}^{8}$, tienen lugar.

Por estas razones, la conciencia histórica no consiste solamente en advertir la situación temporal, contingente y finita de la propia facticidad a través de un proceso dialógico con el otro que comparte la misma experiencia, sino también en encarar a la siempre interpelante tradición en su transformación en mundo mediante un proceso mutuo de posicionamiento: la tradición sitúa al individuo en su mundaneidad y el individuo sitúa a la tradición en cuanto que la reconoce y define como mundo.

Pero este encaramiento no constituye en sí mismo un acto develador, sino sólo una toma de postura, a saber, la postura de resistencia frente a la tradición, que es aquella en la cual se encuentra la intención desmitificadora, es decir, la intención crítica. En ninguna de estas actitudes, sin embargo, desaparece la reiteración de la tradición. Esto es así porque aún la posición

8 Hay que recordar al lector el debate entre la hermenéutica y la crítica de las ideologías, que se desarrolló prácticamente a partir de la publicación de Verdad y Método en 1960, y que involucró nombres como Habermas, Apel, Bubner, Wellmer, Giegel, Bormann y Ricoeur, junto al propio Gadamer (Recas, 2006). 
más acendradamente crítica requiere de un marco normativo que establezca el parámetro (regulativo o utópico) del cual pueda partir toda evaluación de lo real. Pero todo marco regulativo constituye un proyecto porque se erige como orientador de las acciones correctivas de los individuos, con el fin de mejorar las actuales condiciones de vida. Habría que hacer notar, entonces, que la utopía, al ser un proyecto, requiere recuperar lo que es -como decía Heidegger- reiterable de la tradición. Tal vez el esfuerzo de Apel, que lo lleva a establecer una dialéctica entre comunidad ideal de la comunicación y comunidad real de comunicación, pueda ser leído en este sentido9 (Apel, 1985).

La conciencia histórica toma postura frente a la tradición en alguna de las maneras posibles. Si se consideran las cuatro posibilidades enunciadas anteriormente, es posible afirmar que la conciencia histórica puede derivar en actitudes que denotan pertenencia, interpelación y proclividad, además de la actitud crítica, que habría que identificar con la resistencia frente a la tradición. Pero entonces se debe reconocer que en la conciencia histórica es posible encontrar tanto actitudes críticas como acríticas, y aún más, debe reconocerse que la conciencia histórica, para ser tal, no depende de los criterios de verdad como sí ocurre con la ciencia (incluyendo a la ciencia social y a la investigación histórica).

\section{Relatos identitarios e ideología}

Sería importante señalar que en el encaramiento que ocurre ante la tradición, la conciencia histórica se expresa mediante la construcción de relatos identitarios, cuyas características dependerán justamente del modo en que la tradición sea encarada. Estos relatos desarrollan diferentes valores que dependen del tipo de encaramiento frente a la tradición: relatos de pertenencia a una

\footnotetext{
9 Apel establece sus nociones de comunidad real de comunicación y comunidad ideal de comunicación, que se diferencian de las propuestas por Pierce en cuanto que éstas no remiten sólo a un grupo de científicos, sino a toda colectividad humana, ya que desde su perspectiva "en todo juego de lenguaje humano tiene que estar dado a priori el paso posible al discurso argumentativo". De esta forma la argumentación se convierte en el punto clave sobre el cual se asientan no sólo las aspiraciones de verdad científica, sino también las aspiraciones de corrección normativa, la crítica de las concepciones humanas del mundo, la reflexión, la acción racional y la responsabilidad del obrar humano. Con la comunidad ideal de la comunicación, Apel realiza lo que él denomina 'la transformación de la filosofía', es decir, la transformación de la filosofía trascendental tradicional en el sentido de una pragmática lingüística trascendental. Una filosofía que no es la filosofía del sujeto de la conciencia, sino de la comunidad argumentativa.
} 
comunidad específica, relatos de libertad de albedrío al modo de la interpelación de la tradición, relatos que buscan una tradición a la cual sumarse (melancólicos), y relatos que buscan una ruptura con la tradición.

En consecuencia, todos estos relatos, que no deben entenderse necesariamente como relatos escritos, sino como percepciones de mundo, pertenecen al campo de lo ideológico desde la perspectiva con la que Paul Ricoeur adopta el término: como un sistema simbólico integrante, un cuerpo coherente de imágenes, ideas e ideales compartidos, que suministra a los participantes una coherente orientación general en cuanto al espacio y al tiempo (Ricoeur, 1996).

Ricoeur se distancia de Marx y de Althusser para proponer un concepto de ideología que en primera instancia remite a la mediación simbólica de todo acto social, en cuyo caso ésta no será concebida como una deformación de la comunicación, sino como la retórica de la comunicación básica: "Existe una retórica de la comunicación básica porque no podemos excluir del lenguaje los recursos retóricos; éstos constituyen una parte intrínseca del lenguaje corriente. En su función integradora, la ideología es analógicamente básica e ineluctable" (Ricoeur, 1996).

Ante la pregunta de si es posible erigir una ciencia no ideológica, Ricoeur responde negativamente, señalando que esto podría afirmarse solamente en el caso de la ciencia natural, pero no en el de la ciencia social, ya que ésta no satisface los criterios de cientificidad consistentes en la generación de una explicación satisfactoria de fenómenos anteriormente ininteligibles y la resistencia de dichas explicaciones a los intentos de falsación emprendidos sistemática y rigurosamente (Bengoa, 1992, p. 163).

Aun cuando las ciencias sociales no fundamentaran su cientificidad con base en criterios positivistas, sino a partir de la acción crítica, no podrían, desde la perspectiva de Ricoeur, acceder a un estatuto no ideológico, porque, en primer lugar, toda ciencia combativa corre el riesgo de caer en los vicios que denuncia en el adversario. En segundo lugar, porque no puede dar una explicación en términos no ideológicos de la formación de las ideologías, mientras en tercer lugar, porque ella está imposibilitada para realizar una reflexión total, es decir, una reflexión que implique que el sujeto crítico se posiciona más allá de todos sus condicionamientos históricos (argumento fundamental de la hermenéutica gadameriana, por cierto) (Ricoeur, 1988, p. 139). 
Pese a esto Ricoeur reconoce que la acción crítica es posible, si no en su totalidad sí a través de una "relativa autonomía", que el saber puede alcanzar en virtud del factor de distanciamiento incluido en la conciencia histórico-efectual. El distanciamiento del individuo frente a lo otro que forma parte de la relación dialógica del ser fáctico es, para Ricoeur, la condición de posibilidad de una crítica de las ideologías que no se sitúe fuera ni en contra, sino en el seno mismo de la hermenéutica (Bengoa, 1992, p. 164).

Con lo dicho hasta el momento respecto al concepto de ideología propuesto por Ricoeur, puede entenderse mejor que los relatos que la conciencia histórica genera pueden ser tanto ideológicos como críticos respecto a la ideología, pues ésta constituye en primera instancia el medio simbólico que integra toda acción social y, en una segunda instancia, representa el esfuerzo que los individuos y las comunidades hacen por liberarse de situaciones de engaño y dominio que se han vuelto insoportables, pero cuya acción no se encuentra fuera de la tradición.

\section{Comunidad y ética en la experiencia social de la historia}

En El giro lingüístico, Gadamer reconoce la importancia de lograr el acuerdo en virtud de ser conscientes de la existencia de una participación común del mundo entre los individuos, es decir, que pese al carácter fáctico y contingente del ser-en-el-mundo es posible llegar al acuerdo respecto al mundo, de tal manera que la experiencia individual no obstaculiza la puesta en común de importantes afirmaciones respecto a la cosa acerca de la que se habla (Gadamer, 1995, p. 15).

Posteriormente, en un diálogo sostenido con Reinhardt Koselleck (publicado bajo el título de Historia y Hermenéutica), Gadamer señala que este hecho no es asumido de manera pasiva, pues ante esta participación común en el mundo se origina la responsabilidad del ejercicio de la libertad - derivada de encararse frente al entorno y situarlo, mediante designación lingüística, como mundo- asentada en uno mismo, pero que involucra a los semejantes; se trata de la responsabilidad de sí mismo y de sí mismo para con los demás (Gadamer y Koselleck, 1997, p. 100). Esta responsabilidad compartida tiene que ver con el objetivo de buscar incesantemente lo comprensible y el sentido, frente al sinsentido y la absurdidad:

Soy plenamente consciente de que la mirada de quien comprende sigue toda huella de sentido y busca siempre el sentido que le permite abrir 
constantemente, en medio de la insensatez del acontecer y de la historia, algo parecido a horizontes de expectativa, de esperanza, de osadía y de no abyección. Quizás habría que decir que la fuerza suprema del hombre consiste en esto: resistir a todos los desafíos que la realidad nos impone mediante el sin sentido (Unsinn), la demencia (Wahnsinn) y la desconcertante absurdidad (Sinnlosigkeit), y hacerlo perseverando en una búsqueda incansable de lo comprensible y del sentido (Gadamer y Koselleck, 1997, p. 100).

Dado que este diálogo con Koselleck ocurre años después de realizado el debate con Habermas y Apel, es posible sugerir que Gadamer estaba siendo conciliatorio con el punto de vista de la crítica de las ideologías, y que trataba de complementar su propuesta hermenéutica con aquello que sus críticos le extrañaban: una propuesta ética.

Más allá de esta consideración, sin embargo, lo importante del caso radica en que, aunque resulte problemático hablar del sostenimiento de una ciencia crítica meta hermenéutica, esta cuestión estará revestida de la mayor importancia si es que realmente se quiere ofrecer una respuesta desde la hermenéutica, que atienda a las repercusiones éticas de la conciencia histórica. El propio Ricoeur admite la importancia de las consideraciones éticas respecto al papel de la ideología en la sociedad, no sólo por constituir parte fundamental sobre la que se erige la mediación simbólica básica de todo acto social, sino también por la posibilidad de futuro que ofrece. Es por esta razón que señala:

(...) la muerte de las ideologías se convertiría en la lucidez más estéril, ya que un grupo social sin ideología y sin utopía carecería de proyecto, de distancia respecto a sí mismo, de una representación de sí. Sería una sociedad sin proyecto global, en manos de una historia fragmentada en acontecimientos iguales y por consiguiente insignificantes ${ }^{10}$ (Ricoeur, 1988, p. 141).

En este sentido, la propuesta de Apel de tomar en cuenta una comunidad real de comunicación y una comunidad ideal de comunicación, constituye una alternativa que media entre la pretensión de lograr una crítica completamente desligada de la facticidad y una hermenéutica que no desdeñe la importancia de la crítica.

Para hablar de la conciencia histórica es muy importante tener en cuenta, entonces, dos factores que van de la mano: el reconocimiento de la pertenencia

${ }^{10}$ Nótese el acercamiento de Ricoeur a Heidegger cuando dice que la falta de un proyecto hace que la historia sea percibida de manera fragmentada e insignificante; es la forma en cómo vive el Dasein en estado de impropiedad. 
a una comunidad y el posible desarrollo de la crítica desde dentro de dicha comunidad y desde su vida fáctica. Pero ambos elementos no están autoimplicados, pues la conciencia histórica puede encontrar cimentación solamente en el reconocimiento de pertenencia a una comunidad y no desarrollar una actitud crítica al respecto.

Es por ello que en este contexto se habla de la posibilidad crítica de la conciencia histórica, pues constituye una alternativa real, aunque no se cumpla en todos los casos. Desde esta perspectiva, la conciencia histórica no garantizaría la puesta en evidencia de los actos de manipulación porque puede formar parte de ellos, a menos que, efectivamente desarrolle una actitud de rechazo frente a una determinada tradición, en cuyo caso tal vez pueda hablarse de una conciencia histórica crítica, que representaría uno de los modos en los que la conciencia histórica puede manifestarse.

Por su parte, para vivir históricamente, ya sea de manera crítica o no, es necesaria la comunidad, pues ésta constituye siempre el rasero desde el cual un determinado modo de pensar adquiere importancia política en el más amplio sentido de la palabra y, en consecuencia, requiere de una ética que no debe ser entendida necesariamente como desmitificadora, sino como una ética estructuradora de un orden simbólico dado y orientadora de la acción. De este modo, entonces, todo actuar político tiene una dimensión ética, pero sólo determinadas formas del actuar político encuentran en la crítica su justificación para la ética. En la comunidad, la conciencia histórica fundamenta sus nociones de pertenencia e identidad ${ }^{11}$, y también encuentra el ámbito en el cual es posible realizar las acciones derivadas de la asunción de un proyecto. Siguiendo a Heidegger es posible sostener que en la forma en que el Dasein asume la historicidad -de manera resuelta o irresuelta- estaría implicada también la forma en cómo se asume la idea de comunidad: de forma irresuelta es posible encontrar la idea de pertenencia e identidad, pero no volcada a la realización de un proyecto, cosa que se encontraría en la forma resuelta.

\footnotetext{
${ }^{11}$ La identidad es entendida aquí como resultado del interactuar con el mundo que tiene el sujeto con el medio social en el que se encuentra, por lo que en primera instancia ocurre en el ámbito individual, que en una segunda instancia se presenta colectivamente, no en virtud de la creencia en la existencia de un sujeto colectivo sino en la medida en que los individuos comunican sus propios puntos de vista y generan acuerdos sociales, a partir de la conocida fusión de horizontes planteada por Gadamer. La identidad, además, conlleva una historia, que no sólo hace referencia a los acontecimientos del pasado, sino que atiende también a lo que está en construcción en el presente de cara al futuro, por lo que "el concepto de identidad también connota la noción de proyecto" (Toledo, 2012).
} 
El proyecto no implica, en primera instancia, la adopción de una actitud crítica, sino el acto de tomar "en las propias manos" el destino, y evitar de esta manera ser conducido por el mundo de lo impersonal, del uno o man. Asumir, por ejemplo, un proyecto de carácter religioso no implica la realización de acciones críticas comparables a las del científico natural, pero sí actos de argumentación que se realizan en el ámbito comunitario. Esto deriva en dos conclusiones: la primera, que el valor del carácter de resolución que lleva a la conformación de un proyecto no reside en que dicho proyecto tenga fundamentos crítico-científicos, sino sólo existenciarios en la medida en que el individuo asume la responsabilidad de guiar su propia existencia. La segunda conclusión es que aún en el caso de proyectos que no impliquen acciones crítico-científicas, éstos si implican el desarrollo de argumentaciones que se presentan en el ámbito comunitario y que se sancionan y regulan desde éste.

De ahí que sea un gran acierto el que Apel proponga sus comunidades de comunicación, distinguiéndolas de la comunidad de investigadores de Pierce, por el hecho ya señalado de incluir en ellas no sólo a la comunidad científica, sino a toda comunidad que esgrima argumentos y que los someta a la consideración de los demás en busca del acuerdo y del interés común. Al reconocer en la comunidad real de la comunicación el contrapeso fáctico de la comunidad ideal de la comunicación, Apel se aproxima a la idea de que el consenso y la acción crítica pueden lograrse sin la pretensión de situar a los individuos por encima de su propia facticidad, contingencia e historicidad.

\section{A manera de conclusión}

Es importante conocer estos rasgos de la conciencia histórica, porque a partir de la plataforma conceptual que ellos configuran se deriva un nuevo campo de reflexión, que desde el ámbito de la ontología nos conduce al de la ética, sin abandonar el enfoque comprensivo y hermenéutico que ha caracterizado a esta investigación hasta este momento. Esto es así porque de la caracterización de la conciencia histórica, como la puesta en evidencia del Dasein frente a sí mismo, como un acontecer comprensivo y potencialmente crítico en el mundo, deriva la pregunta ¿para qué una conciencia histórica? Esta cuestión involucra tres asuntos fundamentales: 1) A los relatos identitarios a través de los cuales la conciencia histórica se manifiesta socialmente; 2) a la composición ideológica de tales discursos, y 3) a la experiencia social de la historia y de su conciencia como sustrato en el que la conciencia histórica cobra sentido comunitariamente. 
Una de las conclusiones a las que se llega al abordar la conciencia histórica desde una perspectiva hermenéutico-ontológica es que ella no constituye una opción para el ser humano, es decir, no es algo que pueda ser elegible por el hecho de formar parte del ser del ser-en-el-mundo y que, debido a ello, la pregunta del para qué de la conciencia histórica no debe ser pensada desde el plano de lo accesorio. Pero en la medida en que la conciencia histórica pueda ser orientada por una ética argumentativa, como la que Apel propone (1985), la cuestión cobra sentido a un nivel ético, en el cual el quid de la cuestión no es si se debe tener o no tener conciencia histórica, sino qué hacer desde la conciencia histórica que se tiene.

En este escrito se ha insistido en señalar que la conciencia histórica no necesita ser crítica para ser tal, no obstante que la crítica es una posibilidad de la conciencia histórica. Se trata además de una posibilidad deseable, no porque se considere que una conciencia histórica crítica conduzca a una vida más auténtica, sino porque ella puede aportar una orientación razonada que permita realizar las acciones del proyecto que ha sido asumido.

Se pretendería, entonces, en el marco de una perspectiva ética, que las decisiones del individuo busquen ser más autónomas respecto a los dictados de la tradición, aunque no en el sentido de superar ontológicamente su facticidad -hecho imposible por demás-, sino en el de mantener equilibrada la relación dialógica con la tradición y evitar convertirla en un monólogo. La libertad del individuo no residiría, según este marco, en la ruptura de todo condicionamiento histórico, sino en la presencia constante de un sujeto dialogante que hace concesiones al interlocutor, pero que también presenta ante éste sus propias exigencias. El peor de los casos estaría representado por la evasión de la responsabilidad de erigirse como ente dialogante.

Sería ingenuo suponer que en los procesos de diálogo la comunicación acaece de manera transparente, pues, por el contrario, puede estar mediada por un uso estratégico - simulado o abierto- del lenguaje. También resultaría ingenuo suponer que el individuo, como ente dialogante, no emplea eventualmente de manera estratégica el lenguaje: que una persona sea objeto de enajenación de parte de un poder político o mediático no implica que ella misma no haga uso estratégico del lenguaje en otros ámbitos. Asimismo, alguien que política o mediáticamente sea sujeto de dominio en un ámbito determinado, no es un impedimento para ser objeto de dominio en otro ámbito. Las prácticas de dominio no deberían representarse mediante la reducción maniquea de procesos dialógicos que son mucho más complejos. 
El establecimiento del diálogo, en cuanto requiere de la participación de dialogantes activos que no sólo se dedican a entender, sino también a conceder y a exigir -en una palabra: a negociar-, no es o no debería ser ajeno a la coacción, pues ésta constituye un recurso mediante el cual se puede favorecer que se llegue a un acuerdo. Lamentablemente la coacción puede también favorecer un completo rompimiento del diálogo.

La conciencia histórica del sujeto tiene como interlocutor al otro-del-pasado, ante el cual puede reflejarse e identificarse, lo que no implica que no haya exigencias en esta relación dialógica: el pasado tiene sus códigos y sus formas sin cuyo conocimiento no es posible comprenderlo; por su parte, el intérprete del pasado, que actúa desde un presente, no puede conformarse con la comprensión del pasado: necesita ser exigente en términos de lo que el pretérito ha representado y puede representar en cada presente. Si esto no sucede, la relación se reduce, entonces, a un infructuoso intercambio de información.

¿Qué hacer desde la conciencia histórica que se tiene? La respuesta, según lo dicho, sería deseablemente hacer crítica a ella mediante el ejercicio dialogante exigente y dentro de un marco comunitario de sanción, sin entender no obstante este elemento crítico como una superación del nivel ontológico-comprensivo de la facticidad, sino como un ejercicio intersubjetivo de negociación, susceptible del establecimiento de razones ideales válidas mediante la argumentación.

\section{Referencias}

Apel, K. O. (1973). Transformation der Philosophie (Bd. 2). Das Apriori der Kommunikationsgemeinschaft. Frankfurt a. M.: Suhrkamp.

Apel, K. O. (1985). La transformación de la filosofía II. El apriori de la comunidad de comunicación. (Trad. Cortina, A., Chamorro, J y Conill, J). Madrid: Taurus.

Bengoa, J. (1992). De Heidegger a Habermas. Hermenéutica y fundamentación últimas de la filosofía contemporánea. Barcelona: Herder.

Dobrosavljev, D. (2002). Gadamer's Hermeneutics as Practical Philosophy. Facta Universitatis, 2 (9), pp. 605-618. 
Gadamer, H. G. (1995). El giro hermenéutico. (Trad. Parada, A). Madrid: Cátedra.

Gadamer, H. G. (1996). Verdad y Método I. (Trad. Agus Aparicio, A y de Agapito, R). Salamanca: Sígueme.

Gadamer, H. G. y Koselleck, R. (1997). Historia y hermenéutica. (Trad. Oncina, F). Barcelona: Paidós.

Gadamer, H. G. (1998). Verdad y Método II. (Trad. Olasagasti, M). Salamanca: Sígueme.

García, D. E. (2004). Gadamer y la conciencia histórica. La callada herencia viquiana. Acero, J. J et al. (Ed.). El legado de Gadamer (pp. 293-318). Granada: Universidad De Granada.

Heidegger, M. (2002). El ser y el tiempo. (Trad. Gaos, J). México: FCE.

Levinas, E. (1977). Totalidad e infinito. Ensayo sobre la exterioridad. (Trad. Guillot, D). Salamanca: Sígueme.

López, F. M. (2009). Comprensión, lenguaje y mundo. Un esbozo de la ontología hermenéutica de Hans-Georg Gadamer. Guanajuato: Azafrán y Canabrio / Universidad de Guanajuato.

Payne, M. (2002), Terapia narrativa: una introducción para profesionales. Barcelona: Paidós.

Recas, J. (2006). Hacia una hermenéutica crítica. Gadamer, Habermas, Apel, Vattimo, Rorty, Derrida y Ricoeur. Madrid: Biblioteca Nueva.

Ricoeur, P. (1988). Hermenéutica y acción. De la hermenéutica del texto a la hermenéutica de la acción. Buenos Aires: Prometeo Libros.

Ricoeur, P. (1988). Hermenéutica y acción. De la hermenéutica del texto a la hermenéutica de la acción. (Trad. Prelooker, M., Adúris, L., Fornari, A., Gorlier, J. y La Valle, T). Buenos Aires: Prometeo Libros.

Ricoeur, P. (1996). Lectures on Ideology and Utopia. New York: Columbia University Press.

Ricoeur, P. (1996). Lectures on Ideology and Utopia. New York: University Press. 
Ricoeur, P. (1996). Ideología y utopía. (Trad. Bixio, A). Barcelona: Gedisa.

Toledo, M. I. (2012). Sobre la construcción identitaria. Atenea, No. 506. Revisado el 12 de julio de 2020, en: https://scielo.conicyt.cl/scielo. php?script=sci_arttext\&pid=S0718-04622012000200004 